\title{
PERBANDINGAN METODE MFEP DAN MAUT DALAM SELEKSI CALON PESERTA OLIMPIADE SAINS NASIONAL (OSN)
}

\author{
Dewi Maharani* ${ }^{1}$, Andri Nata ${ }^{1}$ \\ ${ }^{1}$ Sistem Informasi, STMIK Royal Kisaran \\ Email: *dewimaharani15@gmail.com
}

\begin{abstract}
OSN (National Science Olympiad) is a competition in the fields of science and science designed by the government to develop students' talents and achievements. OSN is also one of the annual events that students are very interested in honing their abilities in the fields of science and science. In selecting students to be mentored and included in OSN, strict internal selection needs to be done by schools to be able to deliver students to achieve these achievements. During this time the selection made by teachers tends to be subjective, such as by directly referring participants who will take the selection test. Like in the Tamansiswa Sukadamai SMPS research location, so far the teacher selects OSN participants to only focus on those who get 1-3 in the class. The purpose of this study is to help schools select all students who are interested in the Olympics by using Decision Support System technology. Through a comparison of 2 methods, the Multy Factor Evaluation Process (MFEP) and the Multi Attribute Utility Theory (MAUT), researchers will conduct a comparative analysis to obtain more consistent results. Based on the results that have been done, the MFEP method can produce the best prospective participants namely A13 with a value of 16.96. While the MAUT method can produce the best candidate OSN participants namely A5 with a value of 0.680 . This research is expected to be helpful for the selection of prospective OSN participants.
\end{abstract}

Keywords: MFEP; MAUT; National Science Olympiad; decision support system.

\begin{abstract}
Abstrak: OSN (Olimpiade Sains Nasional) merupakan kegiatan perlombaan di bidang sains dan ilmu pengetahuan yang dirancang pemerintah untuk mengembangkan bakat dan prestasi siswa. OSN juga menjadi salah satu ajang tahunan yang sangat diminati siswa dalam mengasah kemampuan dibidang sains dan ilmu pengetahuan. Dalam memilih siswa yang akan dibimbing dan dikutsertakan dalam OSN, seleksi internal yang ketat perlu dilakukan sekolah untuk dapat mengantarkan siswa meraih prestasi tersebut. Selama ini seleksi yang dilakukan guru cenderung subyektif seperti dengan menujuk langsung peserta yang akan mengikuti tes seleksi. Seperti halnya dilokasi penelitian SMPS Tamansiswa Sukadamai, selama ini guru menyeleksi peserta OSN hanya fokus dengan yang mendapatkan ranking 1-3 di kelas saja. Adapun tujuan penelitian ini adalah untuk membantu sekolah menyeleksi seluruh siswa yang berminat dalam olimpiade dengan menggunakan teknologi Sistem Pendukung Keputusan. Melalui perbandingan 2 metode yaitu Multy Factor Evaluation Process (MFEP) dan Multi Attribute Utility Theory (MAUT), peneliti akan melakukan analisis perbandingnan untuk mendapatkan hasil yang lebih konsisten. Berdasarkan hasil yang telah dilakukan, metode MFEP dapat menghasilkan calon peserta terbaik yaitu A13 dengan nilai16,96. Sedangkan metode MAUT dapat menghasilkan calon peserta OSN terbaik yaitu A5 dengan nilai 0,680. Penelitian ini diharapatkan dapat membantu untuk seleksi calon peserta OSN.
\end{abstract}

Kata Kunci : MFEP; MAUT; Olimpiade Sains Nasional, Sistem Penunjang Keputusan 
DOI: https://doi.org/10.33330/jurteksi.v6i3.793

Available online at http://jurnal.stmikroyal.ac.id/index.php/jurteksi

\section{PENDAHULUAN}

OSN (Olimpiade Sains Nasional) merupakan kegiatan perlombaan dibidang sains dan ilmu pengetahuan yang dirancang pemerintah untuk mengembangkan bakat dan prestasi siswa[1][2]. OSN juga menjadi salah satu ajang tahunan yang sangat diminati siswa dalam mengasah kemampuan dibidang sains dan ilmu pengetahuan. Pada tahun 2018, 1.433 siswa yang berkompetisi di ajang OSN. Untuk dapat menjadi peserta dan mendapatkan juara dalam dalam kompetisi ini bukanlah hal yang mudah. Perlu adanya pembimbingan yang intensif kepada siswa yang memiliki potensi. Dalam memilih siswa yang akan dibimbing dan dikutsertakan dalam OSN, seleksi internal yang ketat perlu dilakukan sekolah untuk dapat mengantarkan siswa meraih prestasi tersebut. Selama ini seleksi yang dilakukan guru cenderung subyektif seperti dengan menujuk langsung peserta yang akan mengikuti tes seleksi.

Seperti halnya dilokasi penelitian SMPS Tamansiswa Sukadamai, selama ini guru menyeleksi peserta OSN hanya fokus dengan yang mendapatkan ranking 1-3 di kelas saja. Hal ini dikarenakan minimnya sumber daya untuk melakukan seleksi jika dilakukan bagi seluruh siswa dengan kriteria penilaian yang tidak sedikit. Kondisi ini jelas menghambat siswa lain yang berminat namun tidak juara dikelas. Padahal bisa saja ada siswa yang tidak rangking 1-3 justru memiliki keahlian pada bidang yang diolimpiadekan. Hasilnya, belum ada siswa yang mampu bersaing di tingkat kecamatan. Adapun tujuan penelitian ini adalah untuk membantu sekolah menyeleksi seluruh siswa yang berminat dalam olimpiade tersebut.

Berdasarkan uraian dari

permasalahan di atas, peneliti tertarik untuk melakukan proses penelitian dengan menerapkan teknologi yang dapat menentukan siswa yang layak mengikuti seleksi OSN. Teknologi yang dimaksud yaitu dengan menerapkan sistem pendukung kepu-tusan (SPK). SPK banyak diterapkan dalam bidang pendidikan kesehatan dan manajemen dan lainnya. Teknologi SPK secara fungsi berguna membantu manajemen dalam menganalisis factor/kriteria yang kompleks dan rumit terhadap penilaian suatu alternative dengan memberikan rekomendasi preferensi yang secara umum berbentuk perangkingan[3]. Dalam masalah penelitian ini, penerapan tersebut dilakukan dengan proses perbandingan 2 metode untuk mendapatkan hasil perbandingan yang lebih beragam untuk direkomendasikan kepada pengambil keputusan[4]. Adapun metode yang digunakan adalah Multy Factor Evaluation Process (MFEP) merupakan metode yang menimbang beberapa faktor yang berpengaruh terdahap alternatif[5][6]. Sedangkan metode Multi Attribute Utility Theory (MAUT) merupakan metode yang memiliki rancangan evaluasi dengan bobot dan nilai relavan terhadap alternatif [7].

Metode MFEP didefenisikan sebagai sebuah metode dengan pendekatan sistem pembobotan. Pada sebuah masalah pengambilan keputusan dengan multi kriteria, seorang manajer dapat menilai dan menimbang semua kriteria dengan pendekatan intuitif kuantitatif dalam menilai kriteria apa yang paling penting dalam suatu penilaian alternatif [8].

Berikut merupakan prosedur proses perhitungan menggunakan metode MFEP, antara lain:

1. Menentukan kriteria dan bobot 
kriteria dengan total bobot adalah sama dengan $1(\Sigma$ pembobotan $=1)$.

2. Memberikan nilai pada semua kriteria yang akan dinilai/diproses pada perhitungan yang bersumber dari data-data yang telah dikumpulkan.Yaitu nilai evaluasi kriteria terhadap altenatif dengan interval antara $0-1$.

3. Nilai yang telah didapatkan selanjutnya diproses dengan perhitungan perkalian dengan masing-masing bobotkriteria yang dilanjutkan dengan perhitungan penjumlahan dengan hasil masingmasing perkalian sebelumnya. Evaluasi kriteria diakhiri dengan melihat total dengan ketentuan, total terbesar merupakan yang alternative yang terbaik[9].

Metode MAUT (Multi Atribute Utility Theory) didefenisikan sebagai sebuah algoritma dengan pendekatan menghitung evaluasi akhir (x) pada sebuah nilai elemen $\mathrm{x}$ yang biasa disebut dengan nilai bobot dengan perhitungan penjumlahan dengan nilai bobot dalam dimensinya atau yang biasa disebut dengan utilitas[10].

Langkah pertama yang dilakukan adalah menentukan normalisasi bobot alternatif melalui persamaan berikut,

$U_{(x)}=\frac{x_{i}-x_{j}^{-}}{x_{i}^{+}-x_{j}^{-}}$

dimana :

$U(x)$ =Alternatif dengan yang telah dinormalisasi,

$x i=$ bobot masing-masing alternatif,

$x i-=$ bobot minimum atau terburuk,

$x i+=$ bobot maximum terbaik

Perhitungan utilitas normalisasi atribut didasarkan pada Persamaan 2.

$V_{(x)}=\sum_{i=1}^{n} w_{j} \times x_{i j}$ dimana :

$V(x)=$ nilai keseluruhan dari alternatif pilihan suatu subkriteria,

$W j$ = bobot kriteria,

$X i j=$ nilai alternatif pilihan suatu subkriteria,

$i=$ alternatif pilihan,

$\mathrm{j}=$ subkriteria,

$\mathrm{n}=$ jumlah sampel penelitian

\section{METODE}

Penelitian dilaksanakan di SMP Swasta Taman Siswa Sukadamai dengan jumlah responden sebanyak 6 orang yang bepengalaman dibidangnya. Adapun prosedur/langkah-langkah dari penelitian ini yaitu sebagai berikut :

1. Studi Pustaka

Kajian pustaka bertujuan menemukan dan mempelajari referensi pendukung dalam permsalahan seleksi calon peseta OSN untuk diterapkan ke dalam metode MFEP dan MAUT.

2. Penyusunan Instrumen

Penyusunan instrumen didasarkan pada studi pustaka dan untuk persiapan pengumpulan data.

3. Pengumpulan Data

Pegumpulam data dilakukan dengan menggunakan instrument angket yang telah disiapkan dan divalidasi oleh pakar terkait OSN berupa kriteria maupun alternative yang akan dianalisis.

4. Analisis Data

Analisis dilakukan dalam penelitian melalui perbandingan antara 2 metode SPK yaitu MFEP dan MAUT. Proses perbandingan dilakukan untuk melihat alternati mana yang terbaik antar metode tersebut atau memiliki alternatif sama yang terbaik. 
DOI: https://doi.org/10.33330/jurteksi.v6i3.793

Available online at http://jurnal.stmikroyal.ac.id/index.php/jurteksi

\section{HASIL DAN PEMBAHASAN}

Berdasarkan hasil dari pengumpulan data di lokasi penelitian, data yang dikumpulkan akan diterapkan ke dalam perbandingan dalam penerapan metode MFEP dan MAUT. Berikut ini merupakan langkah penyelesaian metode MFEP.

1. Menentukan faktor dan bobot faktor dimana total pembobotan harus sama dengan 1 yaitu pada tabel 1 . Tabel 1. Factor Weight

\begin{tabular}{|c|c|c|}
\hline Kriteria & Keterangan & Bobot \\
\hline $\mathrm{C} 1$ & Ranking & 0,12 \\
\hline $\mathrm{C} 2$ & Nilai Matematika & 0,27 \\
\hline $\mathrm{C} 3$ & Nilai Fisika & 0,25 \\
\hline $\mathrm{C} 4$ & Nilai Kimia & 0,23 \\
\hline \multirow[t]{2}{*}{ C5 } & Nilai Kepribadian & 0,13 \\
\hline & & 1 \\
\hline
\end{tabular}

Tabel 2. Nilai Faktor dan Alternatif

\begin{tabular}{|c|c|c|c|c|c|}
\hline $\mathrm{A} / \mathrm{C}$ & C1 & C2 & C3 & C4 & C5 \\
\hline A1 & 80 & 100 & 60 & 80 & 90 \\
\hline A2 & 60 & 80 & 95 & 80 & 80 \\
\hline A3 & 60 & 60 & 90 & 70 & 70 \\
\hline A4 & 80 & 100 & 60 & 70 & 70 \\
\hline A5 & 60 & 100 & 80 & 80 & 90 \\
\hline A6 & 100 & 100 & 60 & 60 & 70 \\
\hline A7 & 60 & 80 & 60 & 90 & 80 \\
\hline A8 & 40 & 100 & 80 & 80 & 80 \\
\hline A9 & 100 & 60 & 90 & 70 & 70 \\
\hline A10 & 80 & 100 & 80 & 70 & 70 \\
\hline A11 & 60 & 80 & 80 & 100 & 60 \\
\hline A12 & 60 & 100 & 70 & 70 & 80 \\
\hline A13 & 100 & 80 & 100 & 80 & 60 \\
\hline A14 & 100 & 60 & 80 & 100 & 60 \\
\hline A15 & 80 & 60 & 80 & 60 & 50 \\
\hline \multicolumn{6}{|c|}{$\begin{array}{l}\text { Proses menghitung Weighted } \\
\text { Evaluation }(\mathrm{x}) \text { dengan mengalikan } \\
\text { nilai alternatif dengan Weight } \\
\text { Factor (WF). Berikut perhitungan } \\
\text { bobot dan faktor evaluation. }\end{array}$} \\
\hline a. & $\begin{array}{l}\text { lenga } \\
=0,1 \\
=0,2 \\
=0,2\end{array}$ & $\begin{array}{l}C 1-C \\
80= \\
100 \\
60=\end{array}$ & & & \\
\hline
\end{tabular}

$$
\begin{aligned}
& \mathrm{C} 4=0,23 * 80=18,4 \\
& \mathrm{C} 5=0,13 * 90=11,7
\end{aligned}
$$

Adapun hasil dari perhitungan dari keseluruan alternatif dengan setiap bobot disajikan pada tabel 3 .

Tabel 3. Weight Evaluation (x)

\begin{tabular}{cccccc}
\hline A/C & C1 & C2 & C3 & C4 & C5 \\
\hline A1 & 9,6 & 27 & 15 & 18,4 & 11,7 \\
A2 & 7,2 & 21,6 & 23,75 & 18,4 & 10,4 \\
A3 & 7,2 & 16,2 & 22,5 & 16,1 & 9,1 \\
A4 & 9,6 & 27 & 15 & 16,1 & 9,1 \\
A5 & 7,2 & 27 & 20 & 18,4 & 11,7 \\
A6 & 12 & 27 & 15 & 13,8 & 9,1 \\
A7 & 7,2 & 21,6 & 15 & 20,7 & 10,4 \\
A8 & 4,8 & 27 & 20 & 18,4 & 10,4 \\
A9 & 12 & 16,2 & 22,5 & 16,1 & 9,1 \\
A10 & 9,6 & 27 & 20 & 16,1 & 9,1 \\
A11 & 7,2 & 21,6 & 20 & 23 & 7,8 \\
A12 & 7,2 & 27 & 17,5 & 16,1 & 10,4 \\
A13 & 12 & 21,6 & 25 & 18,4 & 7,8 \\
A14 & 12 & 16,2 & 20 & 23 & 7,8 \\
A15 & 9,6 & 16,2 & 20 & 13,8 & 6,5 \\
\hline
\end{tabular}

b. Berdasarkan hasil Weighted Evaluation (x) diatas, tahapan akhir metode MFEP adalah menghitung total Weighted Evaluation (x).

$\mathrm{XA} 1=9,6+27+15+18,4+11,7=16,34$

$\mathrm{XA} 2=2+21,6+23,75+18,4+10,4=16,27$

$\mathrm{XA} 3=7,2+16,2+22,5+16,1+9,1=14,22$

Adapun hasil dari total dari keseluruhan alternatif disajikan pada tabel 4 .

Tabel 4. Total Weighted Evaluation(x)

\begin{tabular}{ccc}
\hline A/C & Total & RANGKING \\
\hline A1 & 16,34 & 4 \\
A2 & 16,27 & 5 \\
A3 & 14,22 & 14 \\
A4 & 15,36 & 11 \\
A5 & 16,86 & 2 \\
A6 & 15,38 & 10 \\
A7 & 14,98 & 13 \\
A8 & 16,12 & 6 \\
A9 & 15,18 & 12 \\
A10 & 16,36 & 3 \\
A11 & 15,92 & 7 \\
A12 & 15,64 & 9 \\
A13 & 16,96 & 1 \\
A14 & 15,8 & 8 \\
A15 & 13,22 & 15 \\
\hline
\end{tabular}


DOI: https://doi.org/10.33330/jurteksi.v6i3.793

Available online at http://jurnal.stmikroyal.ac.id/index.php/jurteksi

Setelah selesai melakukan penerapan metode MFEP dan menghasilkan perankingan. Selanjutnya dilakukan penerapan dengan metode MAUT, adapun langkah penyelesaiannya sebagai berikut.

1. Pada penerapan metode MAUT, bobot yang digunakan sama dengan metode MFEP diatas, bobot tersebut sesuai dengan tabel 1 .

2. Pada data nilai alternatif dan kriteria, nilai yang diperoleh pun sesuai dengan penerapan metode MFEP sebelumnya, yaitu sesuai pada tabel 2.

3. Selanjutnya melakukan perhitungan matriks normalisasi sebagai berikut.

a. Perhitungan A1 dengan C1-C5

$\mathrm{C} 1=(80-40) /(100-40)=0,667$

$\mathrm{C} 2=(100-60) /(100-60)=1$

$\mathrm{C} 3=(60-60) /(100-60)=0$

$\mathrm{C} 4=(80-60) /(100-60)=0,5$

$\mathrm{C} 5=(90-50) /(90-50)=1$

Adapun hasil dari keseluruhan perhitungan dari matriks normalisasi disajikan pada tabel 5 .

Tabel 5. Matriks Normalisasi

\begin{tabular}{cccccc}
\hline A/C & C1 & C2 & C3 & C4 & C5 \\
A1 & 0,667 & 1 & 0 & 0,5 & 1 \\
A2 & 0,333 & 0,5 & 0,875 & 0,5 & 0,75 \\
A3 & 0,333 & 0 & 0,75 & 0,25 & 0,5 \\
A4 & 0,667 & 1 & 0 & 0,25 & 0,5 \\
A5 & 0,333 & 1 & 0,5 & 0,5 & 1 \\
A6 & 1 & 1 & 0 & 0 & 0,5 \\
A7 & 0,333 & 0,5 & 0 & 0,75 & 0,75 \\
A8 & 0 & 1 & 0,5 & 0,5 & 0,75 \\
A9 & 1 & 0 & 0,75 & 0,25 & 0,5 \\
A10 & 0,6667 & 1 & 0,5 & 0,25 & 0,5 \\
A11 & 0,3333 & 0,5 & 0,5 & 1 & 0,25 \\
A12 & 0,3333 & 1 & 0,25 & 0,25 & 0,75 \\
A13 & 1 & 0,5 & 1 & 0,5 & 0,25 \\
A14 & 1 & 0 & 0,5 & 1 & 0,25 \\
A15 & 0,6667 & 0 & 0,5 & 0 & 0 \\
\hline
\end{tabular}

4. Selanjutnya menghitung total dari perkalian matriks normalisasi dengan bobor sebagai berikut.

$$
\begin{aligned}
\mathrm{A} 1= & (0,12 * 0,667)+(0,27 * 1)+(0,25 * 0) \\
& +(0,23 * 0,5)+(0,13 * 1)=0,595 \\
\mathrm{~A} 2= & 0,12 * 0,333)+(0,27 * 0,5)+(0,25 \\
* & 0,875)+(0,23 * 0,5)+(0,13 * 0,75) \\
= & 0,606 \\
\mathrm{~A} 3= & (0,12 * 0,333)+(0,27 * 0)+(0,25 \\
& * 0,75)+(0,23 * 0,25)+(0,13 * 0,5) \\
= & 0,350
\end{aligned}
$$

Adapun hasil dari keseluruhan perhitungan dari matriks normalisasidengan bobot disajikan pada tabel 6 .

Tabel 6. Hasil Total Matriks Normalisasi

\begin{tabular}{lrr}
\multicolumn{3}{c}{ \& Perankingan } \\
\hline A/C & \multicolumn{1}{c}{ Total } & RANGKING \\
\hline A1 & 0,595 & 6 \\
A2 & 0,606 & 4 \\
A3 & 0,350 & 14 \\
A4 & 0,473 & 10 \\
A5 & 0,680 & 1 \\
A6 & 0,455 & 11 \\
A7 & 0,445 & 12 \\
A8 & 0,608 & 3 \\
A9 & 0,430 & 13 \\
A10 & 0,598 & 5 \\
A11 & 0,563 & 7 \\
A12 & 0,528 & 8 \\
A13 & 0,653 & 2 \\
A14 & 0,508 & 9 \\
A15 & 0,205 & 15 \\
\hline
\end{tabular}

\section{UCAPAN TERIMA KASIH}

Ucapan terimakasih kepada DRPM Deputi Bidang Penguatan Riset Dan Pengembangan Kementerian Riset Dan Teknologi/Badan Riset Dan Inovasi Nasional Sesuai dengan Kontrak Penelitian Tahun Anggaran 2020. 
DOI: https://doi.org/10.33330/jurteksi.v6i3.793

Available online at http://jurnal.stmikroyal.ac.id/index.php/jurteksi

\section{SIMPULAN}

Dari hasil penelitian ini, kriteriakriteria yang dapat diterapkan dalam seleksi calon perserta OSN adalah Ranking, Nilai Matematika, Nilai Fisika, Nilai Kimia, dan Nilai Kepribadian. Perbandingan metode MFEP dan MAUT dapat membantu untuk seleksi calon peserta OSN. Perbandingan tersebut yaitu metode MFEP dapat menghasilkan calon peserta terbaik yaitu A13 dengan nilai 16,96. Sedangkan metode MAUT dapat menghasilkan calon peserta OSN terbaik yaitu A5 dengan nilai 0,680

\section{DAFTAR PUSTAKA}

[1] N. Halimah, "E-JUPEKhu EJUPEKhu," vol. 3, no. September, pp. 41-52, 2014.

[2] J. Inovasi et al., "32|P a g e $33 \mid$ P a g e," vol. 8, no. 1, pp. 32-38, 2018.

[3] M. A. Sembiring, "Penerapan Metode Simple Additive Weighting Sebagai Strategi Pembinaan Kecerdasan Anak," Jurteksi, vol. 4, no. 1, pp. 65-70, 2017 ,

doi: 10.33330/jurteksi.v4i1.35.

[4] B. Prasetyo, W. Laksito, and S. Siswanti, "Sistem Pendukung Keputusan Pemilihan Paket Internet Operator Telekomunikasi Dengan Metode Ahp (Analytical Hierarchy Process)," J. Teknol. Inf. dan Komun., vol. 1, no. 2, pp. 7-12, 2013, doi: 10.30646/tikomsin.v1i2.125.

[5] I. S. Harumy, T.H.F., "Sistem Penunjang Keputusan Penentuan Jabatan Manager," Semin. Nas. Teknol. Inf. dan Multimed. 2016, pp. 6-7, 2016.

[6] D. Y. N. Sri Wahyuni, "DOI : https://doi.org/10.33330/jurteksi.v 6i1.392 METODE AHP DAN METODE MFEP Sekolah Tinggi Manajemen Infromatika dan Komputer Royal DOI https://doi.org/10.33330/jurteksi.v 6i1.392," vol. VI, no. 1, pp. 4350, 2019,

[7] N. Hadinata, "Implementasi Metode Multi Attribute Utility Theory (MAUT) Pada Sistem Pendukung Keputusan dalam Menentukan Penerima Kredit," J. Sisfokom (Sistem Inf. dan Komputer), vol. 7, no. 2, p. 87, 2018, doi: 10.32736/sisfokom.v7i2.562.

[8] M. R. Okaviana and R. Susanto, "Sistem Pendukung Keputusan Rekomendasi Pemilihan Program Studi Menggunakan Metode Multifactor Evaluation Process Di Sma Negeri 1 Bandung," Komputa J. Ilm. Komput. dan Inform., vol. 3, no. 2, pp. 50-57, 2014 ,

doi: 10.34010/komputa.v3i2.2389.

[9] I. Afrianty and R. Umbara, "Sistem Pendukung Keputusan (SPK) Menentukan Kelayakan Calon Penerima Zakat Menerapkan Multi- Factor Evaluation Process (MFEP)," Semin. Nas. Teknol. Informasi, Komun. dan Ind. 8, no. November, pp. 87-94, 2016.

[10] E. Satria, N. Atina, M. E. Simbolon, and A. P. Windarto, "Spk: Algoritma Multi-Attribute Utility Theory (Maut) Pada Destinasi Tujuan Wisata Lokal Di Kota Sidamanik," Comput. Eng. Sci. Syst. J., vol. 3, no. 2, p. 168, 2018, doi: 10.24114/cess.v3i2.9954.: 